\title{
EXCERTOS DA BNCC: DISCUSSÃO DE FUNDAMENTOS E CONSIDERAÇÕES CONCEITUAIS
}

\author{
EXTRACTOS DEL BNCC: DISCUSIÓN DE LOS FUNDAMENTOS Y \\ CONSIDERACIONES CONCEPTUALES
}

\author{
EXCERPTS FROM THE BNCC: DISCUSSION OF FOUNDATIONS AND \\ CONCEPTUAL CONSIDERATIONS
}

Sebastião de Souza LEMES ${ }^{1}$

RESUMO: Nesse primeiro recorte feito em um estudo amplo com certa profundidade teórica objetiva discutir alguns conceitos trazidos pela BNCC $^{2}$ a partir de excertos dos seus fundamentos. $\mathrm{O}$ texto procura, por esse caminho e à luz de uma exploração teórica reflexiva, analisar a complexidade desse universo para o fazer pedagógico no cotidiano da escolarização, pois, considera certa incompletude pela distância existente entre a sua formulação idealizada e a realidade estrutural e conjuntural então apresentados para que "tenham assegurados seus direitos de aprendizagem e desenvolvimento, em conformidade com o que preceitua o Plano Nacional de Educação". Este estudo teórico e exploratório dos conceitos e elementos de narrativa presentes em um "documento de caráter normativo" e com o grau de complexidade instrumental e operacional que se apresenta precisa de indagações e reflexões permanentes sobre sua efetividade, do sistema educacional até à unidade escolar.

PALAVRAS-CHAVE: Sistema educacional. Base Nacional Comum Curricular. Escolarização.

RESUMEN: En este primer corte realizado en un amplio estudio con cierta profundidad teórica se pretende discutir algunos conceptos aportados por el BNCC a partir de extractos de sus fundamentos. El texto busca, por esta vía y a la luz de una exploración teórica reflexiva, analizar la complejidad de este universo para el hacer pedagógico en la escolarización cotidiana, pues considera cierta incompletud por la distancia existente entre su formulación idealizada y la realidad estructural y coyuntural entonces presentada para que "tengan asegurados sus derechos de aprendizaje y desarrollo". Este estudio teórico y exploratorio de los conceptos y elementos narrativos presentes en un "documento normativo" y con el grado de complejidad instrumental y operativa que se presenta necesita de indagaciones y reflexiones permanentes sobre su eficacia, desde el sistema educativo hasta la unidad escolar.

PALABRAS CLAVE: Sistema educativo. Base Curricular Nacional Común. Escolarización.

${ }^{1}$ Universidade Estadual Paulista (UNESP), Araraquara - SP - Brasil. Professor do Departamento de Ciências da Educação e do Programa de Pós-Graduação em Educação Escolar. Editor. ORCID: https://orcid.org/0000-00020750-9294. E-mail: ss.lemes2@gmail.com

${ }^{2}$ Nesse artigo, a Base Nacional Comum Curricular será permanentemente denominada BNCC, uma vez que essa sigla se encontra bastante disseminada na literatura e em diferentes mídias no Brasil.

RPGE- Revista on line de Política e Gestão Educacional, Araraquara, v. 25, n. 3, p. 2193-2211, set./dez. 2021. e-ISSN: 1519-9029 
ABSTRACT: In this first excerpt, made in a broad study with some theoretical depth, the aim is to discuss some concepts brought by BNCC from excerpts from its foundations. The text seeks, in this way and in the light of a reflective theoretical exploration, to analyze the complexity of this universe for the pedagogical practice in everyday schooling, as it considers certain incompleteness due to the distance between its idealized formulation and the structural and conjunctural reality presented to "have their rights to learning and development assured, in accordance with the provisions of the National Education Plan". This theoretical and exploratory study of the concepts and narrative elements present in a "document of a normative character" and with the degree of instrumental and operational complexity that presents itself, still needs permanent inquiries and reflections about its effectiveness, from the educational system to the school unit.

KEYWORDS: Educational system. National Common Curricular Base. Schooling.

\section{Introdução}

O presente artigo, enquanto parte de um estudo mais amplo ainda em desenvolvimento, se propõe discutir, a partir de excertos dos fundamentos apresentados pela $\mathrm{BNCC}^{3}$, alguns conceitos estabelecidos como princípios orientadores de ações que são de grande complexidade teórica e operacional. Tendo em conta que este é um documento de caráter normativo que define o conjunto orgânico e progressivo de aprendizagens essenciais que todos os alunos devem desenvolver ao longo das etapas e modalidades da Educação Básica, de modo a que tenham assegurados seus direitos de aprendizagem e desenvolvimento, em conformidade com o que preceitua o Plano Nacional de Educação (PNE), há que se considerar as condições de instrumentalidade operacional e em caráter permanente de observância e discussão, do sistema até à unidade escolar em seu cotidiano. A dimensão pedagógica nesses princípios adquire um hiper dimensionamento com o imperativo que se reinterprete o ato pedagógico, se ressignifique olhar para o reconhecimento do direito do outro e a própria mentalidade institucional estabelecida historicamente. Nesse contexto, a escolarização, necessariamente inclusiva, afirmará a necessidade do reconhecimento pelo acolhimento da culturalidade, da territorialidade e da diversidade. As necessidades para o atendimento dessas demandas implicam transformações, de certa forma, compreensão e aceitação para submissão, de diferentes ordens com dimensões paradigmáticas, culturais e estruturais. A ética da discussão e do debate são reflexões sobre as condições de possibilidades mínimas de compreensão mútua em situação de troca verbal. Teorizado em particular por Habermas e Karl-Otto Apel, com objetivo de formular as normas que permitam a um debate acontecer de maneira satisfatória.

\footnotetext{
${ }^{3}$ Nesse artigo, a Base Nacional Comum Curricular será permanentemente denominada BNCC, uma vez que essa
} sigla se encontra bastante disseminada na literatura e em diferentes mídias no Brasil. 
Esses autores afirmam também que, em certa leitura da ética (ou teoria) da discussão, a apologia ao debate também é clara na política profissional e no mundo educacional. Apresentada de forma mais precisa, essa teoria (ou ética) mostra que a argumentação oficial é inaceitável, uma vez que democraticamente não se pode aceitar um determinante padrão que não está aberto à discussão e, tampouco, prescindir de examinar a forma como a autoria a formula originalmente e de chamar a atenção para suas dificuldades. Esse artigo assume que só o exercício efetivo do diálogo permite que as normas se efetivem fundadas na razão e expondo a sua complexidade, assim se apropria da teoria da discussão como um instrumento que permite lutar contra o ceticismo axiológico e contra o positivismo jurídico que "investiu o sistema cultural em sua dimensão educacional e penetrou na consciência cotidiana” (JAFFRO, 2001, p. 71-85). Esta discussão propõe uma reflexão sobre as condições e possibilidades de compreensão e pertinência de alguns fundamentos e conceitos em evidência na BNCC. Embora este seja o primeiro extrato de um estudo mais amplo, esse artigo apresenta as primeiras discussões sobre tais temáticas e conceitos tendo em vista o potencial de ação das unidades escolares, pois, considera que nenhuma proposição sistêmica para educação poderá obter êxito significativo se este não for obtido primeiramente na sala de aula no âmbito da unidade escolar.

Os processos de escolarização no Brasil, por motivos que se encontram além de compreensões simples ou fragmentadas, parece que sempre careceu de estudos que possibilitassem a compreensão dos problemas estruturais e indicassem (ou mesmo sugerissem) algo que possibilitasse a sua superação. Entre as inúmeras propostas que historicamente são encaminhadas por diferentes governos observa-se a não permanência e isso faz com que as conquistas de um momento (ou período) se percam no outro. No período atual estamos literalmente estagnados em níveis de desempenho muito baixo na escolarização básica, apesar dos investimentos e das mudanças que ocorreram no período pós LDB de 1996. Conforme os preceitos estabelecidos nessa lei, e considerando as necessidades de superação da fragmentação no sistema escolar, algo absolutamente insuficiente apesar das ações oriundas das políticas educacionais, observa-se a proposição dos planos decenais de educação e se incentiva os debates na perspectiva da construção de uma Base Nacional Comum Curricular que visa garantir um padrão minimamente equânime de aprendizagens a todos nesse processo. Esse deveria ser um instrumento de referência para os conhecimentos mínimos de todos os alunos uma vez que a educação básica é alçada à condição de direito social. Estes debates produziram um documento construído colaborativamente pretendia reduzir as desigualdades de aprendizado, estabelecendo as habilidades e competências fundamentais em cada etapa da educação básica com obrigatoriedade de seu cumprimento. No período atual, como decorrência 
das determinantes do Plano Nacional da Educação PNE - também transformado em Lei espera-se que esta Base Nacional Comum possa nortear os objetivos de aprendizagem e de desenvolvimento na configuração das propostas formativas da escola básica a serem expressas nos projetos pedagógicos e nos currículos das instituições escolares. No entanto, o rompimento e finalização da trajetória de debates, determinada pelo poder público, ao promulgar e publicar essas diretrizes - precocemente ao meu ver - invertem a ordem lógica e pedagógica das discussões em profundidade e cessam-se os debates. Fica evidente que mudanças no ensino básico ocorreriam, porém por outro caminho (SEVERINO; BAUER, 2016), que não pelo aprofundamento das reflexões e debates sobre algumas peculiaridades intrínsecas ao fazer pedagógico na dimensão da unidade escolar e da sala de aula. Do conjunto que até então se produziu e da "súbita" ruptura que encerrou a trajetória dos debates fica, a dimensão pedagógica na escolarização, com ares de contradição ao se manter certa robustez com a ênfase dada no desenvolvimento de competências gerais - cognitivas, pessoais e sociais e comunicativas - assumida como a capacidade e possibilidade de mobilizar e operar conhecimentos em situações de resolução de problemas e tomada de decisões. O que se traz aqui é que a ruptura do debate, que de certa forma deveria ser mais permanente, não permitiu o devido aprofundamento a questões de ordem mais complexa como a dimensão da cognição enquanto um conceito fundamental à BNCC. Considera-se que, no mosaico conceitual que se apresenta para essa estrutura no sistema de ensino, se estará em um emaranhado ainda maior que a questão curricular em si, e esta, por sua vez, tem se apresentado em meio a um conjunto de influências teórico-metodológicas que dificilmente conseguiria orientar com clareza sua aplicação impondo grandes dificuldades para as efetivas ações pedagógicas no processo de escolarização. Menos pela condição dos profissionais envolvidos e muito mais pela insuficiência (ou ausência) estrutural e institucional do sistema, pois, a cognição é um conjunto de processos mentais que se relacionam com a função do conhecimento que envolve memória, linguagem, raciocínio, aprendizagem, inteligência, resolução de problemas, tomada de decisão, percepção e atenção. Implica o desenvolvimento de funções executivas - memória de trabalho, controle inibitório e flexibilidade cognitiva - como competências cognitivas por meio das quais nos possibilita agir de forma organizada na direção de objetivos (DEHAENE, 2015). Assim considerado há que se indagar: Como operar nessa dimensão de complexidade? Que domínios de componentes cognitivas do desenvolvimento deverão ser mobilizadas de acordo com os recursos e estruturas disponíveis para as ações pedagógicas no cotidiano escolar? Essas questões assim postas e diante da difícil compreensão e da atualidade desses conhecimentos, considera-se que, desde às últimas décadas, o professor da Educação Básica tornou-se, de fato, 
a prioridade e isso pode ser visto por meio da quantidade e detalhamento das propostas que orientam a formação e o trabalho docente. Assim, ao se compreender como é organizada, como funciona a estrutura educacional do país e o que se espera de um professor; é preciso se ter claro como ele será valorizado em sua carreira. O sistema educacional, apesar de sua complexidade, é bem estruturado, com definições claras de quais são as responsabilidades das diferentes instituições envolvidas na política de formação docente, por isso, se quisermos ter uma forte, coerente e integrada política para os professores seria preciso instituir um grupo de profissionais que tenham competência técnica e acadêmica capaz de desenhar e implementar uma política nacional de qualidade docente (SEBASTIANI; SUZUKI, 2020, p. 316).

\section{Sobre o conceito de Competências}

Essa complexidade cognitiva se estabelece ao considerarmos os princípios interacionistas que fundamentam concepções centrais da BNCC e traz o conceito de Competência global ${ }^{4}$ e Competência cognitiva, assumido de forma central em sua estrutura.

As produções acadêmicas disponíveis sobre esses conceitos de ordem cognitiva impressionam pela variedade de temáticas que abrangem: as ciências cognitivas, neurobiologia, currículo, aprendizagem e ensino da literacia e da numeracia, autorregulação infantil, distúrbios em diferentes contextos, boas práticas, formação de professores e avaliação (BRASIL, 2020 p. 10). Apesar dos conteúdos complexos, essas produções se apresentam em linguagem de relativa clareza, até onde é possível e acessível, cumpre seu objetivo em termos de divulgação científica. No entanto, há que se considerar que traduzir operacionalmente esses conhecimentos no fazer pedagógico da escolarização e, assim operando, promover o aprendizado e melhorar o desempenho do aluno, tem certa distância e muitos esforços a empenhar. Por esse motivo a maioria dos países estudados estruturou equipes de profissionais de diferentes formas institucionais - Comitês, Institutos Nacionais, Conselhos, entre outros - para que buscassem maneiras para integrar as diferentes ações/intervenções/motivações que a formação docente demanda. Esses grupos estiveram exclusivamente dedicados ao estudo e na elaboração de políticas públicas que pudessem contribuir para a formação e o desenvolvimento dos professores e sua profissionalização. Essa proposição para qualificação é pertinente, uma vez

\footnotetext{
${ }^{4}$ Aqui a competência global é uma capacidade multidimensional. Indivíduos globalmente competentes podem examinar questões locais, globais e interculturais, compreender e apreciar diferentes perspectivas e visões de mundo, interagir com sucesso e respeito com os outros e tomar ações responsáveis para a sustentabilidade e o bemestar coletivo. A dimensão do desenvolvimento na BNCC configura a dimensão dos princípios A relação entre o teste cognitivo de compreensão global e as dimensões da competência global
} 
que esse conceito é compreendido como a mobilização de conhecimentos (conceitos e procedimentos), habilidades (práticas, cognitivas e socioemocionais), atitudes e valores para resolver demandas complexas da vida cotidiana, do pleno exercício da cidadania e do mundo do trabalho (MACEDO; FINNI, 2018). A dimensão de complexidade aqui é imensa e não dispõe de instrumentação suficiente para que se possa aplicar de forma pedagogicamente eficiente, contudo marca a discussão pedagógica e social que tem dado o tom para a dinâmica da escolarização nas últimas décadas e pode ser inferido do texto da LDB, especialmente quando se estabelecem as finalidades gerais do Ensino Fundamental e do Ensino Médio (Artigos 32 e 35). Além disso, desde as décadas finais do século XX e ao longo deste início do século XXI, o foco no desenvolvimento de competências tem orientado a maioria dos Estados e Municípios brasileiros, na construção de seus currículos escolares. É esse também o enfoque adotado considerando os vínculos produzidos por relações internacionais do Brasil e, ao adotar esse enfoque, a BNCC sugere que as decisões pedagógicas devam estar orientadas para o desenvolvimento de competências. Por meio da indicação clara do que os alunos devem "saber" (considerando a constituição de conhecimentos, habilidades, atitudes e valores) e, sobretudo, do que devem "saber fazer" (considerando a mobilização desses conhecimentos, habilidades, atitudes e valores para resolver demandas complexas da vida cotidiana, do pleno exercício da cidadania e do mundo do trabalho), a explicitação das competências oferece referências para o fortalecimento de ações que assegurem as aprendizagens essenciais definidas na BNCC. Segundo a pesquisa elaborada pelo Cenpec, das 16 Unidades da Federação cujos documentos curriculares foram analisados, 10 delas explicitam uma visão de ensino por competências, recorrendo aos termos "competência" e "habilidade" (ou equivalentes, como "capacidade", "expectativa de aprendizagem" ou "o que os alunos devem aprender"). "O ensino por competências aparece mais claramente derivado dos PCN" (p. 75). Nesse contexto, ao longo da Educação Básica, as aprendizagens essenciais definidas na BNCC devem concorrer para assegurar aos estudantes o desenvolvimento de dez competências gerais, que consubstanciam, no âmbito pedagógico, os direitos de aprendizagem e desenvolvimento. Apesar dessa situação onde a perspectiva é importante e legitima, tem-se uma aparente clareza sobre a questão das competências (e habilidades) a serem desenvolvidas pelos que aprendem. Consideramos, contudo, que temos certa insuficiência de respostas, até mesmo de estudos em amplitude e profundidade, sobre questões de ordem aplicada em relação a: como se torna competente? De ordem pedagógica: Que intervenções no fazer cotidiano permitem o desenvolvimento de competências? Há algum estudo no Brasil, como os desenvolvidos pelo Ministério da Educação do Quebec disponível ou integrado à formação docente que, ao examinar detidamente a 
taxonomia competências-habilidades-competências, permitem identificar pelo menos dois tipos de habilidades e estabelecem distinção entre habilidades disciplinares e habilidades transversais? Esse tipo de estudo possibilitou compreender como uma habilidade se desenvolve e o acompanhamento das implicações pedagógicas essenciais inerentes implicadas à implementação de uma reforma baseada no desenvolvimento de competências em sala de aula.

Destacamos que investigações desse tipo aconteceram mais por esforços de pesquisadores individualmente por interesses pessoais, que de organismos com dimensões governamentais, que poucos esforços fizeram nesse sentido. Entre os estudos mais significativos sobre conceitos como de Competências, além do já descrito, está o que se propõe uma discussão um tanto mais ampliado, os estudos do prof. Lino de Macedo. Entre outros estudos dessa temática mostra, cada vez mais, a necessidade de se apropriar de outros domínios no âmbito de conteúdos procedimentais, que estão na ordem do saber fazer. A questões hoje são buscar, encontrar, analisar e interpretar informações em perspectiva de compreender, responder e solucionar problemas ou mesmo apenas ter em si e para si o conhecimento que quiser. Assim, é preciso que se tenha elementos para uma reflexão pedagógica sobre significados das diferentes formas de competências e habilidades disponíveis nos alunos, uma vez que estas se manifestam como condição prévia, como condição do objeto e como competências relacionais. O primeiro caso, como condição prévia do sujeito, herdada ou adquirida segundo o pressuposto cognitivista, considera que nascemos com competências comunicativa, isto é, herdamos a aptidão para o desenvolvimento da linguagem, na língua que herdamos - materna - ou em outras que não são herdadas, porém que podem ser aprendidas e desenvolvidas e se constituem como patrimônio de nossa cultura e de nossas possibilidades de comunicação. Dessa forma, competências e desempenho são e dimensões diferentes. A competências como condição do objeto, independente do sujeito que o utiliza e a competências relacionais. Essa terceira forma de competências é interdependente, ou seja, não basta ser muito entendido em uma matéria, não basta possuir objetos potentes e adequados, pois o importante aqui é o "como esses fatores interagem". As competências relacionais expressam esse jogo de interações que supõe uma abertura para a diversidade. Diversidade de pontos de vista, para as inúmeras formas de se expressar algo e de variabilidade de contextos. Assim, pode-se discutir e argumentar de diferentes modos, há possibilidades para soluções divergentes e há espaço para as diferenças. Essas formas de competência, na prática, não se anulam necessariamente, pois se referem a dimensões diferentes e complementares de uma mesma realidade. Importa compreender essa bidimensionalidade cognitiva onde competência é uma habilidade de ordem geral, enquanto a habilidade é uma competência e ordem particular, específica. Alguns 
resultados (DJELLE OPELY, 2016) mostram também que a atenção seria uma dimensão das competências que se prepara, se desenvolve e sobre a qual não se dá apenas de forma intangível. A atenção do aluno é definida como uma atividade flexível mentalmente, mas também concretamente como uma etapa a ser atravessada do ponto de vista de modelos experimentais considerados. Ainda que como hipótese, pode-se dizer que, se os processos atencionais forem estimulados, isso terá um papel ativo na flexibilidade da atividade mental e, portanto, terá implicações nas competências dos alunos. Nos processos cognitivos estão envolvidas diferentes habilidades cognitivas que o cérebro usa para pensar, aprender, lembrar, raciocinar e prestar atenção. Particularmente a questão da atenção, como um estado composto pelo conjunto de mecanismos pelos quais o cérebro seleciona as informações, direciona seu processamento e, considerando a capacidade de permanência nesse estado, em cada um individualmente, essa habilidade desempenha papel importante na realização de tarefas desde as mais complicadas às menos complexas e, apesar de frequentemente apresentados como tópicos separados, de alguma forma, estão relacionados (DEHAENE, 2015). Durante alguns processos cognitivos, essas habilidades podem se sobrepor. M. Posner (2006) distingue pelo menos três sistemas de atenção: alerta, que modula globalmente o nível de vigilância; o foco de atenção, que seleciona um objeto e o controle executivo, que seleciona a cadeia de processamento apropriada para uma determinada tarefa e controla sua execução. Nesse sentido, observe-se que, ao se praticar a leitura é preciso que a atenção - enquanto um estado focal controlado e dirigido - seja mantida nessa condição e possibilite a memória reter e recuperar o texto que acabou de ler. Sem qualquer desses requisitos não seria uma leitura qualificada, ou mesmo se teria a retenção e recuperação do que foi lido. Aqui pode-se indagar à BNCC: num contexto assim descrito, como espera que elementos de ordem pedagógica possam estimular tais processos cognitivos e, ao mesmo tempo, manter o controle dos sistemas de atenção? O que trazemos aqui para estas reflexões são pistas e indícios da complexidade envolvida na dimensão da cognição humana e que, operar com ela circunscrita ao processo de escolarização, estrutural e institucionalmente, estará fadado a resultados insuficientes.

\section{Considerações e compromisso da/na BNCC}

Um outro destaque a se considerar e discutir são os compromissos estabelecidos com a educação integral. A sociedade contemporânea, segundo a BNCC, impõe um olhar inovador e inclusivo às questões centrais do processo educativo que indaga: o que aprender, para que aprender, como ensinar, como promover redes de aprendizagem colaborativa, como avaliar o 
aprendizado, entre outras. No novo (sic) cenário mundial, reconhecer-se em seu contexto histórico e cultural, comunicar-se, ser criativo, analítico-crítico, participativo, aberto ao novo, colaborativo, resiliente, produtivo e responsável requer muito mais do que o acúmulo de informações. Requer o desenvolvimento de competências para aprender a aprender, saber lidar com a informação cada vez mais disponível, atuar com discernimento e responsabilidade nos contextos das culturas digitais, aplicar conhecimentos para resolver problemas, ter autonomia para tomar decisões, ser proativo para identificar os dados de uma situação e buscar soluções, conviver e aprender com as diferenças e as diversidades. Mais uma vez, nessas reflexões há, de forma endógena ao processo de escolarização, uma percepção simplificadora dessa complexidade com suas impossibilidades instrumentais e operacionais estruturalmente disponível, pois, não se pode desenvolver a educação integral sem a educação inclusiva. Por princípios constitucionais o conceito de educação como direito, agrega pedagogicamente ao conceito de inclusão ${ }^{5}$ o respeito à diversidade de necessidades e de estilos cognitivos e de aprendizagem.

A discussão e reflexão que trago nesse ponto é que a educação integral é um sistema aberto, completo e adaptado que considera as necessidades específicas de ensino e aprendizagem de todas as crianças e jovens assegurando o atendimento as suas necessidades, aspectos e possibilidades de desenvolvimento.

Entre outras dimensões estão sutilmente envolvidos o desenvolvimento dos sentidos, o domínio do caráter, a aquisição de valores humanos essenciais, o desenvolvimento de um sentido ético e estético, o aperfeiçoamento metódico e compreensivo das faculdades mentais (observação, concentração, memorização, imaginação, raciocínio). Os sistemas de ensino que sempre formam desiguais agora tem na educação integral sua alternativa inclusiva, acolhedora e humanizadora (FORTIER et al., 2018). A Educação Básica, assim posta, implica compreender a complexidade e a não linearidade desse desenvolvimento, estabelecendo um marco de ruptura com visões reducionistas que privilegiam ou a dimensão intelectual (cognitiva) ou a dimensão afetiva. Isso significa estabelecer uma necessária visão plural e integral da criança, do adolescente, do jovem e promover uma escolarização voltada ao seu acolhimento, reconhecimento e desenvolvimento pleno (BRASIL, 2018).

Em um certo sentido, parece haver alguma incompreensão em relação a distância que separa a inclusão, para além da discussão semântica, da integração/interação escolar, pois,

${ }^{5}$ (N/A) Para além da ação ou efeito de acolher; acolhida; do modo de receber ou maneira de ser recebido com a devida consideração. Boa acolhida; hospitalidade. O trazer para si enquanto um lugar onde há segurança; abrigo e uma certa corresponsabilidade pelo desenvolvimento, pela integração/interação. 
enquanto a inclusão reconhece que todos sejam integrados, incorporados e acolhidos, a integração/interação, por outro lado, no processo de escolarização reconhece essa necessidade, porém não atua na promoção da intervenção (reconstrução) estrutural necessária para que ocorra o acolhimento. Para tanto, é necessário que se atue sobre as bases conceituais e fundamentais dos conteúdos escolares democratizados e os eixos de construção dos currículos que, como núcleos de saberes formadores constituintes um suporte epistêmico universal e estruturantes no processo de escolarização, considere a expressão das experiências culturais e individuais do sujeito que aprende. Além disso, aqui, é preciso que se atente para esses conteúdos curriculares, sua disciplinarização e sua distribuição com uma abordagem de ensino interdisciplinar caracterizada, em primeiro lugar, por um cruzamento de pontos de vista sobre um objeto comum de estudo. É a referência pautada nesses núcleos de saberes que possibilita as reflexões por uma ótica epistemológica e se expressa na concepção de nuclearidade ${ }^{6}$ conceitual e curricular. Essa ótica qualifica a reflexão, em atos, ao reconhecer e promover a interdisciplinaridade ${ }^{7}$ como uma necessidade epistêmica e prática diante da complexidade do universo educativo e, com efeito, cada disciplina também vai contribuir com algo para um projeto comum, mas não necessariamente sendo a mesma coisa ou do mesmo jeito; é como uma inteligência coletiva onde diferentes disciplinas vão trabalhar juntas, criar links e formar projetos comuns para o trabalho pedagógico. A interdisciplinaridade, planejada a priori, porém, de posse do diagnóstico com perfil de sua(s) turmas, deverá favorecer a elaboração de atividades integradoras para que o acolhimento escolar permita, ao alunado, a integração, compreensão e aprendizagem e, ao conjunto da unidade escolar, o acolhimento. Destaca-se, contudo, que é principalmente o aluno quem integra na interdisciplinaridade e não apenas os professores, gestores e demais participantes na dinâmica escolar. Essa lógica, a priori aberta à interdisciplinaridade, ao encontrar os detratores com suas adversativas ( imediatamente ao se defrontar com a falta de recursos e com os obstáculos organizacionais, financeiros, epistémicos e metodológicos na estrutura. Neste momento, o “desejo" e os

${ }^{6}$ Concepção assumida pelo autor para atribuir a condição de núcleo aos conceitos essenciais dos conteúdos específicos em cada disciplina e, por extensão, a mesma condição aos elementos essenciais da organização curricular na unidade escolar configurados no Projeto Pedagógico.

7 A interdisciplinaridade caracterizada por meio da confluência de múltiplos processos cujas inter-relações constituem a estrutura de um sistema que funciona como uma totalidade organizada, que denominamos sistema complexo (GARCÍA, 2011). No contexto aqui apresentado essa complexidade se evidencia como um processo de articulação entre várias disciplinas que não se limita a um simples acréscimo de conhecimentos heterogêneos. Sem pretender uma teoria unificada, o que equivaleria ao nascimento de um novo paradigma, é, pelo contrário, necessário ter em conta a diversidade de posturas epistemológicas que contribuem para a colaboração do processo interdisciplinar. (DARBELLAY, 2011). 
esforços na perspectiva do desenvolvimento interdisciplinar se esvai no tempo e são colocados no esquecimento, tanto no campo acadêmico quanto na rede de ensino.

A transição da integração escolar para a escolarização inclusiva é algo desafiador, principalmente aos professores em suas representações da implementação desse ambiente no âmbito da escola. A integração/interação escolar é um assunto muito sensível para os professores quando se trata de receber a $\mathrm{PcD}^{8}$ às suas aulas pelas dificuldades estruturais, instrumentais e operacionais nos mais diferentes tipos de necessidades que possam apresentar. $\mathrm{Na}$ formação dos novos professores e no desenvolvimento profissional dos que já estão na carreira docente parece não haver espaço para um aperfeiçoamento funcional em sua atuação como docente inclusivo e, além disso, todos têm suas representações para o trato com a inclusão, mas, nem todos, se predispõem a esse acolhimento de forma efetiva e satisfatória. $\mathrm{O}$ apoio à construção de comunidades escolares e educacionais inclusivas ${ }^{9}$, de equipes escolares com o devido aprimoramento funcional e políticas inclusivas de estado, seriam de grande importância em ambos os processos, tanto na formação inicial e contínua de professores como na reflexão necessária e permanente sobre essa questão. Implementar a educação inclusiva implica compromisso permanente e contínuo com a aprendizagem profissional e com o preparo, psicológico e emocional, do conjunto desses agentes para o acolhimento. É preciso se ter em conta que a capacidade de resposta às exigências contextuais é fundamental, a especialidade é necessária e as redes integradas de apoio são imprescindíveis. Essas componentes são mais bem compreendidas se considerarmos a complexidade, uma vez que estas comunidades de aprendizagem operam na confluência de uma série de sistemas em interação e consideram a possibilidade de mudança, já que, nesse contexto, a aprendizagem do professor ocorre por meio da recontextualização do conhecimento e para além de fronteiras estanques. Essas questões emergem quando se busca enfatizar necessidades como a colaboração e o desenvolvimento de culturas e práticas sociais inclusivas nas, e para além, das escolas. No Brasil, temos a expressão "acolhimento educacional especializado" (Atendimento Educacional Especializado, AEE), desde a Constituição Federal de 1988 e está associada à ideia de que os alunos nesta AEE devem ser educados preferencialmente em escola regular, mas seguindo um tratamento diferenciado, ou seja, o AEE. No entanto, apenas depois de duas décadas se definiu "esse conceito em um documento de política, como um conjunto de atividades e recursos educacionais que promovam a acessibilidade, organizados de forma institucional e oferecidos para a formação do aluno." (MENDES; SANTIAGO; ANTUNES, 2018). As referidas comunidades escolares e

\footnotetext{
${ }^{8}$ Denominação adotada por Convenção das Nações Unidas para designar Pessoa com Deficiência - PcD.
}

${ }^{9}$ Ver em maior profundidade a discussão sobre essas comunidades no artigo de Walton et al. (2019). 
educacionais inclusivas podem ser de grande valia para garantir esta AEE aos alunos (públicoalvo) da educação especial, este é um serviço de apoio que pode/deve ser construído na escola.

No contexto da educação básica atual, a BNCC tem sido considerada como um marco curricular regulador no processo de escolarização que, também, orienta e procura garantir a organização dos planos de ação educacionais e administrativos do conjunto institucional de um sistema de ensino que pretende, democraticamente, atender as demandas educativas da sociedade com equidade. Se propõe orientar programas de estudo com clareza conceitual e compromisso institucional a partir do qual poderá fazer gestão no processo de desenvolvimento curricular. Impõe-se para tanto que um processo de educação inclusiva seja para além da escola e que sejam estabelecidos pelo menos três componentes: a educação (escolar) humana integral, o acesso aos serviços de saúde e o atendimento lato ao paciente.

Nesse momento e contexto, não me parece deslocado trazer à luz dessas considerações um pouco sobre o tipo ideal de escola democrática que, desde o final do século XVIII, apresenta essa questão sobre a educação escolar com dimensão jurídica e política. Os discursos emblemáticos do filósofo e matemático Condorcet e no projeto de decreto sobre a organização geral da educação pública, apresentado na Assembleia Legislativa abril de 1792, pode-se destacar objetivo da escola explícito nos seguintes termos: "Proporcionar a todos os indivíduos da espécie humana os meios de prover as suas necessidades, de assegurar o seu bem-estar, de conhecer e exercer os seus direitos, de ouvir e cumprir os seus deveres; assegurar que todos tenham a facilidade (...) de desenvolver toda a gama de talentos que receberam da natureza e, assim, estabelecer a igualdade de fato entre os cidadãos e fazer com que a igualdade política real seja reconhecida por lei.” Nesse contexto histórico, há um segundo elemento relacionado ao acesso à educação para todos: "Assim, a educação deve ser universal, ou seja, estender-se a todos os cidadãos" (CONDORCET, 1929). Na história da educação brasileira, as primeiras referências à educação integral remontam à década de 1930, incorporadas ao movimento dos Pioneiros da Educação Nova e em outras correntes políticas da época, nem sempre com o mesmo entendimento sobre o seu significado.

Assim posto, fica evidente que esses princípios não são novos e que há uma persistente inoperância dos esforços da sociedade brasileira nesse sentido, ao buscar (ou não) responder a essa demanda. A compreensão da escola, como espaço de diálogo e de formação; de aprendizagem e de democracia inclusiva, ainda nos é algo distante instrumental e operacionalmente, mas não é assim em nossas reflexões sobre o fazer pedagógico na escola ou criticamente em relação as insuficiências das políticas públicas estabelecidas para a educação básica. É como se nos encontrássemos permanentemente desinstrumentalizados para operar 
nesses princípios, seja pela complexidade trazida pela inclusão seja pela inviabilidade técnica e estrutural da educação formal no Brasil. Há uma sensação de que o modelo de escola já, há algum tempo, encontra-se em estado de esgotamento de suas possibilidades estruturais para cumprir suas finalidades institucionais educativas e, apesar de organizacionalmente cumprir suas funções, apresenta resultados que exigem a requalificação processual do desempenho.

Na perspectiva apresentada no pacto Interfederativo a implementação da BNCC propõe, entre outros, o princípio do respeito ao acolhimento da igualdade, da diversidade e da equidade no processo de escolarização. Assim, fica para a escola internamente, a dificuldade para implementar e operar com a proposta e a reponsabilidade da superação do conservadorismo de nosso modelo tradicional de escolarização, o estímulo à sua aplicação na vida real, a importância do contexto para dar sentido ao que se aprende e ao protagonismo do estudante em sua aprendizagem e na construção de seu projeto de vida. A BNCC ao levar em conta que o Brasil, ao longo da história, naturalizou "desigualdades educacionais" em relação ao acesso e a permanência dos estudantes na escola e ao seu aprendizado, reconhece a herança socio educacional e escolar inadequada, estrutural e institucionalmente, tanto para o momento atual quanto para as perspectivas de qualificação da escolarização básica.

A BNCC especifica a autonomia dos entes federados e destaca a acentuada diversidade cultural com profundas desigualdades sociais, ainda assim, orienta que os sistemas e redes de ensino construam seus currículos e que, no âmbito das unidades escolares, precisam elaborar propostas pedagógicas que considerem as necessidades, as possibilidades e os interesses dos estudantes, isso, vai muito além das questões de escolarização. Nesse contexto, há também uma necessidade social, territorial ${ }^{10}$ e comunitária, pois, dessa forma serão consideradas suas identidades linguísticas, étnicas e culturais.

Aqui se revela o estado de esgotamento do modelo existente. Ao se ler na BNCC que "são amplamente conhecidas as enormes desigualdades entre os grupos de estudantes definidos por raça, sexo e condição socioeconômica de suas famílias" (BRASIL, 2018, p. 13), parece que nesse ponto não se considera, entre outras, a questão, multicultural presente na diversidade da sociedade brasileira. Esse contexto é onde o Projeto Pedagógico de cada unidade escolar precisa se construir e ser implementado, assim, de forma autônoma, poderá dinamizar e qualificar o fazer pedagógico no cotidiano da formação básica. Entretanto, é preciso considerar essa realidade vivencial para além das dificuldades técnicas e pedagógicas de ordem operacional, uma vez que, entre outras, há aquelas que se pode considerar como obstáculos dissimulados na

${ }^{10}$ Nesse texto concebemos o território conforme discutido por Adalgisa Sposati (2013) e Paul E. Little (2002). 
cultura escolar, como a mentalidade meritocrática e culturalista que atribui o fracasso de alguns às causas de ordem cultural (FORQUIM, 1993, p. 126) e, nesse sentido, constitui-se uma postura radicalmente contraria a concepção de uma escola plural conforme estabelecido nos princípios do estado democrático de direito. Importa esclarecer que o pensamento culturalista sustenta que existe uma deficiência cultural e não uma diferença cultural. Pela diferença cultural não há como sustentar uma cultura menor ou mesmo as denominadas subculturas, mas, tão somente, outras culturas além da cultura dominante. Assim posto, a questão da escolarização inclusiva e, consequentemente, do currículo tornam-se ainda bem mais complexas (LEMES, 2003). A BNCC, em seu pacto federativo, seus princípios de igualdade, diversidade e equidade, explicita que "as aprendizagens essenciais que todos os estudantes devem desenvolver e expressa, portanto, a igualdade educacional sobre a qual as singularidades devem ser consideradas e atendidas. Essa igualdade deve valer também para as oportunidades de ingresso e permanência em uma escola de Educação Básica" (BRASIL, 2018, p. 13); então, depreendese aqui se colocar em destaque o princípio da democracia da/na escola como espaço/ambiente de diversidade, diálogo e de formação. Nesse contexto, a inconclusividade do termo democracia, seu emprego e sentido polissêmico possibilita que o estado estabeleça (imponha?) regulamentações com excesso de detalhamento que tende a cercear (quase imobilizar) a dimensão pedagógica que, por sua vez, em grande parte do seu tempo, aguarda orientações, ordens e, por vezes autorização para agir. Essa (quase) imobilidade interfere diretamente na autonomia da escola para tomar decisões básicas na rotina própria da vida escolar e em seu Projeto Pedagógico que deixa de significar uma condição de trabalho que as próprias escolas estabelecem, para ser algo outorgado por normas regulamentares e diretrizes de ação comuns a todo sistema. Assim, a unidade escolar perde a materialidade de sua proposta para o ensinar e o aprender e assume uma condição heterônoma em relação ao sistema produzindo um esvaziamento do significado pedagógico (AZANHA, 1992). Parece que os determinantes da escola democratizada, no âmbito da BNCC, redefiniram o conceito para a unidade escolar eximindo-a de competência para tomar decisões e agir envolvendo a comunidade, a localidade ou a territorialidade. Ainda assim, a referida Base, apresenta que,

as decisões curriculares e didático-pedagógicas das Secretarias de Educação, o planejamento do trabalho anual das instituições escolares e as rotinas e os eventos do cotidiano escolar devem levar em consideração a necessidade de superação dessas desigualdades. Para isso, os sistemas e redes de ensino e as instituições escolares devem se planejar com um claro foco na equidade, que pressupõe reconhecer que as necessidades dos estudantes são diferentes. De forma particular, um planejamento com foco na equidade também exige 
um claro compromisso de reverter a situação de exclusão histórica que marginaliza grupos - como os povos indígenas originários e as populações das comunidades remanescentes de quilombos e demais afrodescendentes - e as pessoas que não puderam estudar ou completar sua escolaridade na idade própria. Igualmente, requer o compromisso com os alunos com deficiência, reconhecendo a necessidade de práticas pedagógicas inclusivas e de diferenciação curricular, conforme estabelecido na Lei Brasileira de Inclusão da Pessoa com Deficiência (Lei no 13.146/2015) (BRASIL, 2018, p. 15 , grifo nosso $)^{11}$.

Isto posto, consideramos que nossos grifos devem ser, no mínimo, melhor analisados por conta de seu distanciamento organizacional da escola entre proposição-ação no processo e necessidades em diferentes realidades, por isso indagamos: há instrumentação operacional da unidade escolar para tanto? Há o devido preparo dos recursos humanos e disponibilidade material/instrumental para essas ações? Os fundamentos (desejos?) apresentados no documento da BNCC parecem bastante completo, mas impregnado de subjetividades e com grandes dificuldades operacionais aumentadas por conta da centralidade administrativa, decisória e de gestão que desconsidera a própria complexidade, limita os espaços de ação e autonomia das unidades escolares para ajustes e mudanças fundamentais no atendimento das demandas especificas. Importa observar e considerar que, do ponto de vista de uma escolarização democrática e da necessária autonomia da unidade escolar, não se exime a Administração/Gestão do Sistema de Ensino da responsabilidade de fixar e prover as diretrizes e as metas advindas de uma política pública para a educação, mas é preciso que se estabeleça claramente o espaço de ação da unidade escolar, de acordo com seu projeto pedagógico, em sua comunidade e no seu âmbito territorial de atuação e influência. Atribuímos uma grande importância à questão territorial por ser este espaço um ambiente vivencial do acontecer cotidiano; por ser o espaço socializado definido e delimitado por e a partir de relações que nele se estabelece, é onde o processo educativo se origina, se desenvolve, atua e interfere na escolarização. Essa é a componente mais forte para sustentação do fazer pedagógico na unida de escolar, por isso considero inquietante que a BNCC não trate ou faça referência ao Projeto Pedagógico, em suas 600 páginas de proposições orientadoras para a escolarização básica, apenas na página $405^{12}$ há, uma única referência que tangencia essa componente ao explicitar que,

${ }^{11}$ Os destaques nos grifos foram feitos com o propósito de se evidenciar os elementos com um alto grau de subjetividade, complexidade e a necessidade de instrumentalização multiprofissional. Há, também, elementos que compõem mazelas renitentes historicamente na educação brasileira. Dificuldades que se mantém há décadas e, algumas delas, a pelo menos um século.

${ }^{12}$ Existem inúmeras versões desse "manual"; a que estou utilizando para análise, com 500 páginas, traz a referência ao Projeto Pedagógico apenas na página 405 e no contexto apresentado na citação. 
Convém observar que é pressuposto dos objetos de conhecimento, no Ensino Fundamental - Anos Iniciais, analisar como o sujeito se aprimorou na pólis, tanto do ponto de vista político quanto ético. Entretanto, respondendo aos desafios contemporâneos marcados por grandes movimentos populacionais e pela globalização, considerou-se uma nova dimensão para o projeto pedagógico (BRASIL, 2018, p. 405, grifo nosso).

Parece que a BNCC pressupõe assumir parte desse papel e que suas orientações e diretrizes atendem às demandas das especificidades e peculiaridades locais das ações pedagógicas na unidade escolar inclusivas originadas nesse espaço vivencial da estrutura.

\section{REFERÊNCIAS}

AZANHA, J. M. P. Uma idéia de pesquisa educacional. São Paulo: Edusp/Fapesp, 1992.

AZANHA, J. M. P. Autonomia da Escola, um Reexame. Palestra realizada no Seminário A Autonomia na Escola Pública, promovido pela Fundação para o Desenvolvimento da Educação. São Paulo: Secretaria de Estado da Educação, 1992.

AZANHA, J. M. P. A democratização no ensino como expansão de oportunidades. In: CONGRESSO ANUAL DA SOCIEDADE BRASILEIRA PARA O PROGRESSO DA CIÊNCIA, 31., 1979, Fortaleza. Anais [...]. Fortaleza, CE: SBPC, 1979.

BERNSTEIN, B. Pedagogy, symbolic control and identity: theory, research, critique. London: Taylor \& Francis, 1996.

BONAMINO, A.; BRANDÃO, Z. O currículo: tensões e alternativas. Cadernos de Pesquisa, São Paulo, n. 92, p.16-25, fev. 1995.

BRASIL. Plano Nacional de Educação PNE 2014-2024. Brasília, DF: Instituto Nacional de Estudos e Pesquisas Educacionais Anísio Teixeira, 2015. 404 p.

BRASIL. Ministério da Educação. Base Nacional Comum Curricular. Brasília, DF: MEC, 2018.

CARTA de Punta del Leste. Estabelecimento da aliança para o progresso dentro da estrutura da operação pan-americana. Revista Brasileira de Política Internacional, Rio de Janeiro, v. 4, n. 16, p. 157-172, dez. 1961.

CONDORCET, M. Cinco memorias sobre educação pública. Buisson, Condorcet. Paris: Livraria F. Alcane, 1929. p. 59-75.

CONDORCET, J. A. N. C. Cinq mémoires sur l'instruction publique. Paris: Flammarion, 1993. 
FORTIER, M.-P. et al. Intégration scolaire, éducation inclusive et représentations des enseignants: de la formation initiale à la communauté éducative. Revue des sciences de l'éducation, v. 44, n. 1, p. 12-39, 2018. DOI: https://doi.org/10.7202/1054156ar

WALTON, E. et al. What matters in learning communities for inclusive education: a crosscase analysis. Professional Development in Education, v. 48, n. 1, p. 134-148, 2019. DOI: https://doi.org/10.1080/19415257.2019.1689525

MENDES, E. G.; SANTIAGO, M. C.; ANTUNES, K. C. V. Les perspectives de l'éducation inclusive au Brésil. Trad. Hélène Bréant. Revue internationale d'éducation de Sèvres. Paris, 2018.

JAFFRO, L. Habermas et le sujet de la discussion. Dans Cités, v. 1, n. 5, p. 71-85, 2001.

LITTLE, P. E. Territórios sociais e povos tradicionais no brasil: por uma antropologia da territorialidade. Departamento de Antropologia do Instituto de Ciências Sociais. Brasília, DF: UNB, 2002.

DARBELLAY, F.; LOUVIOT, M.; MOODY, Z. L'interdisciplinarité à l'école. Succès, résistance, diversité. Éditions Alphil-Presses universitaires suisses. Neuchâtel, Suisse, 2019.

DARBELLAY, F. Vers une théorie de l'interdisciplinarité? Entre unité et diversité. Nouvelles perspectives en sciences sociales - Revue internationale de systémique complexe et d'études relationnelles. Sur le thème de l'interdisciplinarité, v. 7, n. 1, 2011.

DJELLE OPELY, P.-A. Flexibilite cognitive et competence des eleves. De l'etablissement secondaire Jean Piaget. International Journal of Current Research, v. 8, n. 04, p. 29133 29141, Apr. 2016.

BEHAR, P. A. Competências em Educação a Distância. Porto Alegre, RS: Penso, 2013.

LE BOTERF, G. Avaliar a Competência de um Profissional: três dimensões a explorar. Reflexão RH, Lisboa, v. 1, n. 1, p. 60-63, jun. 2006. Disponível em: http://www.guyleboterfconseil.com/Article\%20evaluation\%20version\%20directe\%20Pessoal.pdf. Acesso em: 11 set. 2020 .

LE BOTERF, G. De la Compétence. Essai sur un attracteur étrange. Paris: Les Éditions d'Organisation, 1994.

LEMES, S. S. A escolarização e o pluralismo cultural; reflexões, buscas e algumas pistas para solução de embates. In: FONSECA, D. J. (Org.). Cadernos de formação em fundamentos sociológicos e antropológicos da educação. São Paulo: UNESP, 2003. p. 79-82.

LEMES, S. S. O caminho da escola democratizada: pistas e perspectivas para o Currículo. In: Gestão das unidades escolares: Organização e Gestão da Escola. Gestão Curricular. São Paulo: Cultura Acadêmica: UNESP, 2019.

LOVELESS, T. Between the State and the Schoolhouse: Understanding the Failure of Common Core (Educational Innovations Series). Harvard Education Press, 2021. ISBN 10: 1682535908. ISBN 13: 9781682535905. 
MACEDO, L.; FINI, M. I. Uma análise do conceito de competências na BNCC. Revista Pátio Ensino Médio, Profissional e Tecnológico, Porto Alegre, n. 37, 2018.

MORETTO, V. P. Reflexões Construtivistas sobre Habilidades e Competências. Dois Pontos: Teoria \& Prática em Gestão, Belo Horizonte, v. 5, n. 42, p. 50-54, maio/jun. 1999.

OECD. Global Competency for an Inclusive World. Paris: OECD, 2016. Disponível em: http://www.oecd.org/pisa/aboutpisa/Global-competency-for-an-inclusive-world.pdf. Acesso em: 10 set. 2020.

PERRENOUD, P. Construir as Competências desde a Escola. Porto Alegre, RS: Artmed, 1999.

PERRENOUD, P. Dez Novas Competências para Ensinar: convite à viagem. Porto Alegre, RS: Artmed, 2000.

PERRENOUD, P. Ensinar: agir na urgência, decidir na incerteza. 2. ed. Trad. Cláudia Schilling. Porto Alegre, RS: Artmed, 2001.

PERRENOUD, P. As Competências para Ensinar no Século XXI: a formação dos professores e o desafio da avaliação. Porto Alegre, RS: Artmed, 2002.

PIAGET, J. Vontade e Ação. Trad. Pitsa Hartocollis. Porto Alegre, RS, 1999. 4 p.

PIAGET, J. Epistemologia Genética. 3. ed. São Paulo: Martins Fontes, 2007.

ROLANDO, G. Interdisciplinariedad y sistemas complejos. Revista Latinoamericana de Metodología de las Ciencias Sociales, 2011. Disponível em:

http://www.memoria.fahce.unlp.edu.ar/art_revistas/pr.4828/pr.4828.pdf. Acesso em: 10 set. 2020.

SCHNEIDER, D.; SILVA, K. A.; BEHAR, P. A. Competências dos atores da educação a distância: professor, tutor e aluno. In: BEHAR, P. Competências em Educação a Distância. Porto Alegre, RS: Penso, 2013.

SCHNEIDER, D. MP-Comp EAD: modelo pedagógico baseado em competências para professores e para tutores em educação a distância. 2014. 298 f. Tese (Doutorado em Educação) - Faculdade de Educação, Universidade Federal do Rio Grande do Sul, Porto Alegre, 2014. Disponível em: http://hdl.handle.net/10183/94705. Acesso em: 11 jul. 2017.

SPOSATI, A. Território e gestão de políticas sociais. Serviço Social em Revista, Londrina, v. 16, p. 05-18, jul./dez. 2013.

STOER, S. R. Construindo a escola democrática através do "campo da recontextualização pedagógica”. Educação, Sociedade \& Culturas, Porto, n. 26, p. 133-14, 2008.

UNESCO. Oficina Regional de Educación de la Unesco para América Latina y el Caribe. Laboratorio Latinoamericano de Evaluación de la Calidad de la Educación (LLECE). 
Disponível em: http://www.unesco.org/new/es/santiago/education/education-assessmentllece. Acesso em: 23 mar. 2020.

ZABALA, A.; ARNAU, L. Como Aprender e Ensinar Competências: uma proposta para o currículo escolar. Porto Alegre, RS: Artmed, 2010.

\section{Como referenciar este artigo}

LEMES, S. S. Excertos da BNCC: discussão de fundamentos e considerações conceituais. Revista on line de Política e Gestão Educacional, Araraquara, v. 25, n. 3, p. 2193-2211, set./dez. 2021. e-ISSN:1519-9029. DOI: https://doi.org/10.22633/rpge.v25i3.15837

Submetido em: 10/08/2021

Revisões requeridas em: 12/09/2021

Aprovado em: 17/10/2021

Publicado em: 08/12/2021 